Editorials represent the opinions of the authors and not necessarily those of the BMJ or BMA

\section{EDITORIALS}

For the full versions of these articles see bmj.com
Cordelia E M Coltart clinical adviser to the president, Royal College of Physicians, London NW1 4LE, UK

Ian T Gilmore chair of UK

Alcohol Alliance, Royal College of Physicians, London NW1 4LE, UK igilmore@liverpool.ac.uk

Competing interests: None declared.

Provenance and peer review: Commissioned; not externally peer reviewed

Cite this as: BMJ 2011;342:d1063 doi: 10.1136/bmj.d1063

\section{bmj.com}

- Personal view: Vary

VAT on alcohol: a more

palatable way to achieve

minimum pricing?

(BM) 2010;341:c6573)

Editorial: Preventing

alcohol related harm

to health

(BMJ 2010;340:C372)

\title{
Minimum alcohol pricing in England
}

\section{A start, but not enough}

Since the $B M J$ last highlighted the health harms of alcohol, ${ }^{1}$ there has been a welcome acknowledgement by government in England that cheap drink is an important factor in driving these harms. Ministers recently revealed plans to set a minimum price by imposing a ban on selling alcohol for less than the combined tax and duty paid on it. This would result in minimum prices of $€ 0.21$ (€0.25; $\$ 0.34$ ) per unit of beer and $€ 0.28$ per unit of spirits, which equate to $€ 0.38$ for a can of weak lager, $£ 2.03$ for a bottle of wine, and $€ 10.71$ for a litre of spirits. Although, in principle, this is an important step, in practice the price floor has been set so low that it will have no effect whatsoever on the health of the nation.

On the positive side, for the first time recent statistics suggest an overall reduction in harm associated with alcohol, with a $6 \%$ decline in alcohol related deaths and $6 \%$ reduction in consumption in 2009. ${ }^{2}{ }^{3}$ However, these are data from a single year on a background of marked increases in consumption and harm since the 1990s. Furthermore, the burden of alcohol to the United Kingdom remains substantial, with the latest data reporting 3000040000 deaths a year, 863300 hospital admissions a year, and alcohol related economic costs of $€ 20 \mathrm{bn}-55 \mathrm{bn}$ a year. ${ }^{4}$ In addition, some key indices continue to worsen at a worrying rate-for example, hospital admissions in young people (16-24 year olds) are rising fast (www.hesonline. nhs.uk).

The recent fall in consumption may be one of the few benefits of the recession, but it highlights the strong association between economic affordability and alcohol consumption. ${ }^{5}$ This reinforces the need for alcohol pricing policies. International evidence strongly supports the notion that modulating price substantially reduces alcohol consumption and associated harms, but how is it best done? Increases in duty can be effective, but these increases particularly hit on-licence traders such as pubs. It is home drinking that has escalated, and big chain supermarkets can offset the effect of duty increases through discounting and special offers. Conversely, setting a minimum unit price can differentially affect the offlicence trade and has been supported by, among others, the last chief medical officer for England, ${ }^{6}$ the Academy of Medical Sciences, ${ }^{7}$ and the House of Commons Health Committee. $^{4}$

The proposed targets set by the government are less than half the $£ 0.50$ a unit minimum recommended by health professionals. Recent UK estimates suggest that a $£ 0.50$ minimum price per unit would lead to 3393 fewer deaths, 97900 fewer hospital admissions, 45800 fewer crimes, 296900 fewer sick days, and a total saving

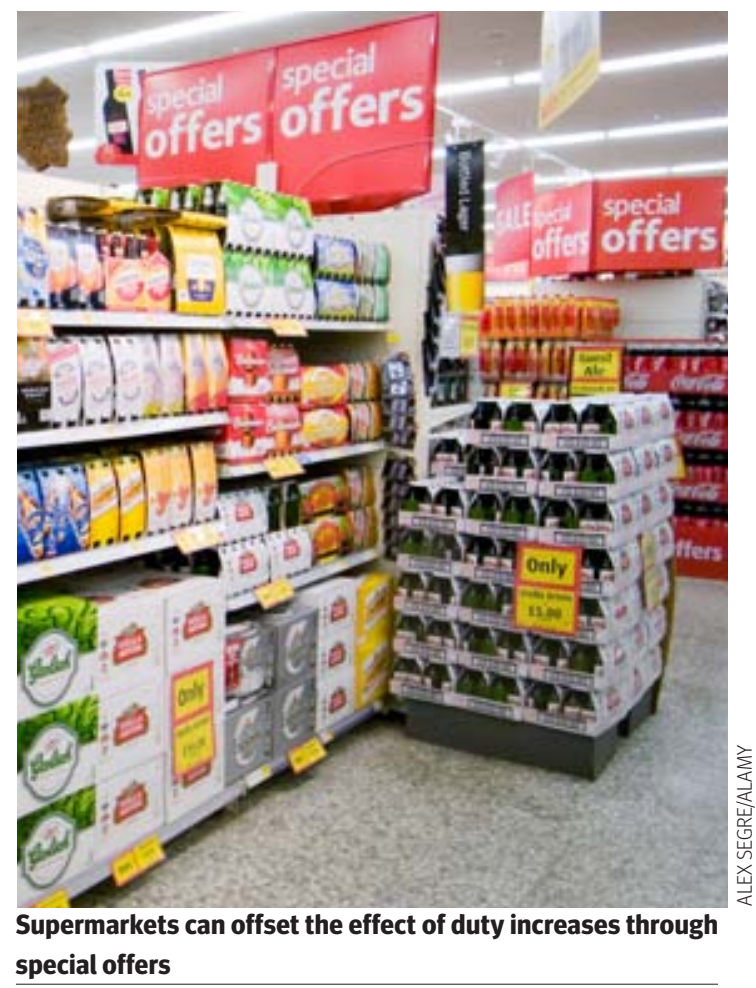

of $€ 15$ bn over 10 years. ${ }^{8}$ It is estimated that $75-80 \%$ of alcohol is consumed by the $20-25 \%$ of people who misuse it. Any pricing policy will mainly target heavy drinkers, who buy 15 times more alcohol than moderate drinkers, spend 10 times as much a year, and pay $40 \%$ less per litre of pure alcohol through cheaper preferences. ${ }^{8}$ Concerns that minimum unit price might affect the average British family were allayed by recent calculations showing that the overall effect should be a reduction in average weekly supermarket bills for most people, who would no longer be subsidising alcohol purchases for the harmful and hazardous drinker. ${ }^{9}$

Several other proposed policy developments are worthy of note. Firstly, reduced measures of alcohol may be soldfor example, wine in measures of less than $75 \mathrm{ml}$ and beer in two thirds of a pint. ${ }^{10}$ Secondly, the government intends to introduce a new additional duty on beers over $7.5 \%$ abv (alcohol by volume) to decrease the consumption of cheap, "super strength" lagers, which are primarily associated with hazardous drinking behaviours. ${ }^{11}$ Although the principle of differential duty by strength is sound, this strong beer accounts for a tiny fraction of beer sales, so the change will have little effect at the population level. Finally, the government plans to incorporate businesses 
- Discuss minimum pricing of alcohol on doc2doc at http://bit.ly/iiurpV into public health strategy decisions (including alcohol), to achieve positive societal change through "responsibility deals" incorporating the "nudge" theory. However, the history of voluntary partnerships with the drinks industry since the Alcohol Harm Reduction Strategy of 2004 has been at best disappointing.

Successive governments (with the notable exception of brave attempts in Scotland) have been reluctant to risk upsetting either the voter or the drinks lobby through championing evidence based regulation on price, availability, and marketing. They have failed to heed the advice of the House of Commons Health Committee report that stated "we are concerned that government policies are much closer to, and too influenced by, that of the drinks industry and the supermarkets than those of expert health professionals such as the Royal College of Physicians or the CMO [chief medical officer]." ${ }^{4}$ This risks leaving the most vulnerable in society-the under-aged and the poorest-exposed to cheap, available, and skilfully promoted offers. It is particularly crucial to target young drinkers to try to break the well documented cycle of transition to chronic alcohol abuse in later life. Let us hope that the new direction of travel, though unlikely to have any immediate effect on health, signals a move towards more evidence based policy. Health must be foremost in policy decisions and not take a back seat to commercial interests.

1 Groves T. Preventing alcohol related harm to health. BMJ 2010;340:c372.

2 Office for National Statistics. Alcohol deaths. UK rates fall in 2009. 2011. www.statistics.gov.uk/cci/nugget.asp?id=1091.

British Beer and Pub Association. Statistical handbook. 2010.

4 House of Commons Health Committee. Alcohol: first report of session 2009-10. www.publications.parliament.uk/pa/cm200910/cmselect/ cmhealth/151/15102.htm.

5 Anderson P, Chisholm D, Fuhr DC. Effectiveness and cost-effectiveness of policies and programmes to reduce the harm caused by alcohol. Lancet 2009;373:2234-57.

6 Donaldson L. 150 years of the annual report of the chief medical officer on the state of public health in 2008. Department of Health, 2009. www. dh.gov.uk/en/Publicationsandstatistics/Publications/AnnualReports/ DH_096206.

7 Academy of Medical Sciences. Calling time-the nation's drinking as a major health issue. 2004. www.acmedsci.ac.uk/p48prid16.html.

8 Meier P, Brennan A, Purshouse R. Independent review of the effects of alcohol pricing and promotion: part B. 2008. www.dh.gov.uk/en/ Publichealth/Healthimprovement/Alcoholmisuse/DH 4001740.

9 Record C, Day C. Britain's alcohol market: how minimum alcohol prices could stop moderate drinkers subsidising those drinking at hazardous and harmful levels. Clin Med 2009;9:421-5.

10 Department for Business, Innovation and Skills. More freedom to buy and sell bread and wine. 2011. http://nds.coi.gov.uk/content/detail. aspx?NewsAreald=2\&ReleaselD=417278.

11 HM treasury. A review of alcohol taxation. 2010. www.hm-treasury. gov.uk/d/alcohol_tax_review301110.pdf.

\section{High blood pressure in young people and premature death}

\section{Alternative strategies are needed to stratify risk and determine treatment thresholds}

\section{RESEARCH, p 483}

Bryan Williams professor of medicine, Department of Cardiovascular Sciences and the Leicester NIHR Cardiovascular

Biomedical Research Unit

in Cardiovascular Diseases,

University of Leicester, Leicester

LE3 9QP, UK

bw17@le.ac.uk

Competing interests: None declared.

Provenance and peer review: Commissioned; not externally peer reviewed.

Cite this as: BMJ 2011;342:d1104 doi: $10.1136 / \mathrm{bmj} . \mathrm{d} 1104$
In the linked cohort study, Sundström and colleagues followed more than 1.2 million young Swedish army conscripts over a 37 year period to assess the relation between blood pressure in late adolescence and subsequent cardiovascular mortality and total mortality. ${ }^{1}$

Blood pressure values track from childhood, indicating a slow process of disease evolution-a process that is now accelerated by the rise in childhood obesity. The clinical dilemma is when to intervene with lifestyle interventions and treatment. ${ }^{2}$ The problem with guidelines is that they are based on evidence from clinical trials with hard clinical end points such as coronary heart disease, stroke events, or death. Such events occur mainly in older people, so younger people with high blood pressure are largely excluded from the trials.

Furthermore, using cardiovascular risk assessment to stratify younger people for treatment is problematic because young people are at low short term risk and are thus unlikely to reach the required risk threshold for treatment. The decision about what to do with younger people with high blood pressure has also been compounded by a lack of data about the relation between blood pressure in the young and the subsequent risk of death.

The challenge to acquire such data is formidable. Studies would need to assess large numbers of people over long periods to be able to detect a significant change in mortality. Sundström and colleagues have risen to the challenge in their study, which followed up more than one million young men over 37 years. The men studied had been conscripted between 1969 and 1995 and had undergone medical examination, including careful blood pressure measurement, at conscription. ${ }^{1}$ In Sweden a unique personal identification number (linked to the Swedish Causes of Death Registry) is assigned to every citizen, and this allowed the investigators to describe the association between baseline blood pressure, subsequent death, and cause of death. During follow-up, nearly 30000 people died (2.4\%), $12.5 \%$ of whom died of cardiovascular disease, a similar rate to those dying from cancer.

High blood pressure in younger people most commonly manifests as a raised diastolic pressure, ${ }^{3}{ }^{4}$ and the relation between baseline diastolic pressures and subsequent total mortality and cardiovascular mortality was strikingly positive. The risk of death rose sharply above a diastolic pressure of around $90 \mathrm{~mm} \mathrm{Hg}$. It is remarkable that a single supine blood pressure measured in adolescence shows such a monotonic and positive association with risk of premature death. This observation extends the well recognised association between raised blood pressure and mortality risk in older people to very young people. ${ }^{5}$ What differs is that in older populations-the majority of people with hypertension-systolic pressure matters more in defining hypertension and the risks associated with it. This is because of the progressive rise in systolic pressure from mid-life and the corresponding decline in diastolic pressure. ${ }^{4}$ Important caveats are that the study population was exclusively male and white, so the applicability of the findings to women and other ethnic groups is unknown. In addition, the study was 
unable to capture data on nonfatal cardiovascular events, such as non-fatal but disabling stroke and heart disease, an important consideration with regard to the potential benefits of treatment.

The relation between baseline systolic blood pressure and total and non-cardiovascular mortality was more complex, and not as striking. The relation seemed to be U shaped, with the lowest mortality being at a systolic blood pressure of around 130 mm Hg. ${ }^{1}$ This U shaped association was most striking for noncardiovascular mortality and was graded, so it was not solely driven by people with very low systolic pressures at baseline. The reason for this U shaped systolic pressure association with non-cardiovascular mortality is unclear, particularly as details of the main causes of non-cardiovascular mortality are limited to "external causes," suicide, and cancer. Nevertheless, confirmation of this finding and further study of a potential link between lower systolic pressure in youth and higher subsequent non-cardiovascular mortality seems warranted.

So, what does this mean for clinical practice? The data links diastolic blood pressure in youth with subsequent premature mortality and points to a threshold of diastolic blood pressure of $\sim 90 \mathrm{~mm} \mathrm{Hg}$ above which mortality risk is clearly increased. The data for systolic pressure are less easy to interpret because of the more complex association with total mortality. If the analysis is limited to cardiovascular mortality, a systolic pressure of $160 \mathrm{~mm} \mathrm{Hg}$ would yield the same hazard of cardiovascular mortality as a diastolic blood pressure of $90 \mathrm{~mm} \mathrm{Hg}$ in younger people. However, these data do not tell us whether therapeutic lowering of blood pressure at these thresholds would necessarily reduce risk in younger people.

The real clinical dilemma is when to treat blood pressure in younger people-those under 40 years and especially those at the younger end of this age spectrum. These new data support consideration of lifestyle changes and therapeutic interventions in younger people with a diastolic blood pressure over $90 \mathrm{~mm} \mathrm{Hg}$ and a systolic blood pressure over $160 \mathrm{~mm} \mathrm{Hg}$. However, the data do not tell us how safe or effective such interventions would be and whether younger people with lower levels of systolic pressure should also be considered for treatment. Consequently, clinicians need to use alternative strategies to stratify risk in younger people with raised blood pressure. Such strategies should define whether their blood pressure is already damaging the cardiovascular system via markers of target organ damage such as retinopathy, albuminuria, or left ventricular hypertrophy. Put another way, it is easy to stratify risk in older people because we have data from intervention trials showing the benefits of treatment. Stratifying risk in younger people is more complex and requires more detailed study of the consequences of blood pressure on cardiovascular structure and function-a recognised harbinger of future risk. Further studies are needed to define how best to stratify risk in younger people with raised blood pressure and their need for treatment.

1 Sundström J, Neovius M, Tynelius P, Rassmussen F. Association of blood pressure in late adolescence with subsequent mortality: cohort study of Swedish male conscripts. BMJ 2011:342:d643.

2 Williams B. Hypertension in the young-preventing the evolution of disease versus the prevention of clinical events. J Am Coll Cardiol 2007:50:840-42.

3 Burt VL, Whelton P, Roccella El, Brown C, Cutler JA, Higgins M, et al. Prevalence of hypertension in the US population. Hypertension 1995;25:305-13.

4 Franklin SS, Jacobs MJ, Wong ND, L'Italien GJ, Lapeurta P. Predominance of isolated systolic hypertension among middle aged and elderly US hypertensives: analysis based on National Health and Nutrition Examination Survey (NHANES III). Hypertension 2001;37:869-74.

5 Lewington S, Clarke R, Qizilbash N, Peto R, Collins R. Age-specific relevance of usual blood pressure to vascular mortality: a meta-analysis of individual data for one million adults in 61 prospective studies. Lancet 2002;360:1903-13.

6 Williams B, Lindholm LH, Sever PS. Systolic pressure is all that matters. Lancet 2008;371:2219-21.
Cite this as: $B M J$ 2011;342:d1048 doi: 10.1136/bmj.d1048

\section{Statins for primary prevention of cardiovascular disease Are not needed for people at very low risk and should be tailored to individual risk in everyone else}

The case for prescribing statins to people with atherosclerotic cardiovascular disease is strong, and it is realistic to attribute the improved survival largely to the effects of these drugs. ${ }^{1}{ }^{2}$ The case for statins in men and women without existing cardiovascular disease is less clear and was highlighted in a recent Cochrane systematic review. ${ }^{3}$

The review, slightly more restrictive in its inclusion criteria than other recent analyses which typically considered twice as many people, looked at 14 trials of about 34000 people with no evidence of cardiovascular disease. The review found that in people taking statins, all cause mortality-on average $1 \%$ per year of observation-was reduced by $17 \%$, fatal and non-fatal coronary heart disease by $28 \%$, fatal and non-fatal stroke by $22 \%$, and the rate of revascularisation by $34 \%$ over 


\section{Jaap W Deckers doctor,}

Thoraxcenter, Department of

Cardiology, Cardiovascular

Research Institute Erasmus

University Rotterdam (COEUR),

3015 CE Rotterdam, Netherlands

j.deckers@erasmusmc.nl

Roger S Blumenthal professor

of medicine and cardiology,

Department of Cardiology, Johns

Hopkins Ciccarone Center for

the Prevention of Heart Disease,

Baltimore, MD, USA

Competing interests: None declared.

Provenance and peer review:

Commissioned; not externally peer reviewed.

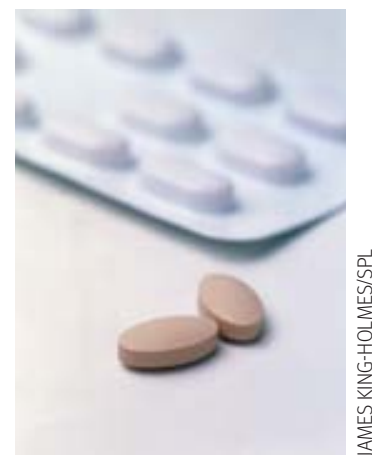

- Follow the discussion, Statins - the ultimate drugs? on doc2doc at http://bit.ly/i25116 a period of three to four years. Comparable numbers have been reported in other recent meta-analyses, ${ }^{4-7}$ so it is safe to assume that the beneficial effects of statins are substantial for coronary heart disease and coronary revascularisation, more modest for stroke, and probably between $10 \%$ and 15\% for overall mortality. Debate on the best "true" estimates of these risk reductions may be intellectually interesting but has limited practical relevance; the real question is which relatively healthy people qualify for initiation of-in principle-lifelong treatment with statins?

The authors of the Cochrane review conclude that the benefits of statins will outweigh harm if the risk of cardiovascular events exceeds $2 \%$ a year. That threshold is similar to current guidelines in the United States and not unlike the most recent European guidelines. ${ }^{18}$ Of note, comparable risks of cardiovascular disease have been reported in low risk patients with stable coronary artery disease. ${ }^{9}$ Before discussing the most appropriate threshold of risk to start preventive medical treatment, it is useful to consider how best to assess future risk in people without clinical evidence of cardiovascular disease.

Although the most logical answer is to use risk prediction models, such models do have shortcomings. ${ }^{10}$ Resulting estimates are based on averages, their discriminatory power and accuracy are limited, and the level at which treatment starts depends on small differences in risk. By definition, the group at the highest calculated risk comprise a small proportion of the total burden of cardiovascular disease: the largest number of cardiovascular events will not occur in the relatively small numbers of people at highest risk, but in the much larger pool of people at lower (average or "intermediate") risk. Interestingly, no study has shown that the use of prediction models improves clinical outcomes, but it is generally thought that risk factor management should be more aggressive in those with the highest risk of future disease.

Having said that, cholesterol and blood pressure values are usually only moderately raised, and actual risk is largely determined in the various risk prediction models by age and sex. This means that men qualify for preventive interventions much earlier than women. Women usually develop cardiovascular disease at a later age, and often in more mature forms such as non-ST segment elevation myocardial infarction, stroke, and heart failure as opposed to ST elevation infarction (and sudden death) in men. By the time women develop clinical manifestations, "silent" atherosclerotic disease may already be extensive, and, in addition to statins, more extensive treatment such as antihypertensive agents could well be in order.

Other methods to assess the risk of cardiovascular disease use specific biomarkers, such as high sensitivity $\mathrm{C}$ reactive protein measurement, or imaging techniques such as computed tomography. ${ }^{11}$ Substantial coronary calcification is clearly associated with a worse outcome, but it has not been shown conclusively that the use of such techniques reduces clinical complications compared with the usual risk assessment, especially in a cost effective way.

It must be remembered that cholesterol lowering treatment is only one part of the ABCDE approach to preventing cardiovascular disease-Assessment of risk to determine eligibility for aspirin and lipid lowering; Blood pres- sure control; Cholesterol management and cessation of Cigarette smoking; Dietary improvement; and Exercise. ${ }^{12}$ Clinicians need to become better at helping patients make sustained improvements in their lifestyle habits. In particular, in relatively young people, such interventions will have long lasting effects and could prevent unnecessary medicalisation.

Evidence from basic science and clinical trials clearly shows that statins reduce morbidity and mortality from cardiovascular disease in the primary prevention setting. In the era of generic statins it is much easier to justify lowering cholesterol in a middle aged or older person with multiple risk factors. There are few downsides because more than $90 \%$ of people will tolerate the drug with no problem. Given the large effects of statins on events such as heart attack, coronary revascularisation, and stroke, they may also be cost effective. Because we now have more or less universal agreement about their effects, the cost effectiveness of low cost statins-which was not extensively covered in the Cochrane review-warrants further study.

In view of the evidence, statins should be seriously considered in people with diabetes at least by age 50 in men and 60 in women. Also, men aged 55 years or above with multiple risk factors, and women aged 65 years or above, should be seriously considered for generic statin use. In elderly people, a relatively low dose of statin may be sufficient and, certainly in the presence of hypertension, additional antihypertensive treatment may be needed given the strong association between the development of stroke and heart failure in the elderly.

1 Graham I, Atar D, Borch-Johnsen K, Boysen G, Burell G, Cifkova R, et al. European guidelines on cardiovascular disease prevention in clinical practice: executive summary: Fourth Joint Task Force of the European Society of Cardiology and Other Societies on Cardiovascular Disease Prevention in Clinical Practice. Eur Heart) 2007;28:2375-414.

2 Randomised trial of cholesterol lowering in 4444 patients with coronary heart disease: the Scandinavian Simvastatin Survival Study (4S). Lancet 1994;344:1383-9.

3 Taylor F, Ward K, Moore TH, Burke M, Davey Smith G, Casas IP, et al. Statins for the primary prevention of cardiovascular disease. Cochrane Database SystRev 2011;1:CD004816.

4 Brugts JJ, Yetgin T, Hoeks SE, Gotto AM, Shepherd J, Westendorp RG, et al. The benefits of statins in people without established cardiovascular disease but with cardiovascular risk factors: meta-analysis of randomised controlled trials. BMJ 2009;338:b2376.

5 Ray KK, Seshasai SR, Erqou S, SeverP, Jukema JW, Ford I, et al. Statins and all-cause mortality in high-risk primary prevention: a meta-analysis of 11 randomized controlled trials involving 65,229 participants. Arch Intern Med 2010;170:1024-31.

6 Thavendiranathan P, Bagai A, Brookhart MA, Choudhry NK. Primary prevention of cardiovascular diseases with statin therapy: a meta-analysis of randomized controlled trials. Arch Intern Med 2006;166:2307-13.

7 Mills EJ, Rachlis B, Wu P, Devereaux PJ, Arora P, Perri D. Primary prevention of cardiovascular mortality and events with statin treatments: a network meta-analysis involving more than 65000 patients. J Am Coll Cardiol 2008;52:1769-81.

8 Grundy SM, Cleeman JI, Merz CN, Brewer HB Jr, Clark LT, Hunninghake $\mathrm{DB}$, et al. Implications of recent clinical trials for the National Cholesterol Education Program Adult Treatment Panel III guidelines. Circulation 2004;110:227-39.

9 Braunwald E, Domanski MJ, Fowler SE, Geller NL, Gersh BJ, Hsia J, et al. Angiotensin-converting-enzyme inhibition in stable coronary artery disease. NEnglJ Med 2004;351:2058-68.

10 Pasternak RC, Abrams J, Greenland P, Smaha LA, Wilson PW, Houston-Miller N. 34th Bethesda Conference: task force 1-identification of coronary heart disease risk: is there a detection gap? J Am Coll Cardiol 2003;41:1863-74.

11 Greenland P, Alpert JS, Beller GA, Benjamin EJ, Budoff MJ, Fayad ZA, et al. 2010 ACCF/AHA guideline for assessment of cardiovascular risk in asymptomatic adults: executive summary: a report of the American College of Cardiology Foundation/American Heart Association task force on practice guidelines. JAm Coll Cardiol 2010;56:2182-99.

12 Blumenthal RS, Michos ED. The HALTS trial-halting atherosclerosis or halted too early? NEnglJ Med 2009;361:2178-80. 


\section{Pandemic influenza vaccines}

\section{Are protective, but are limited by delays in availability}

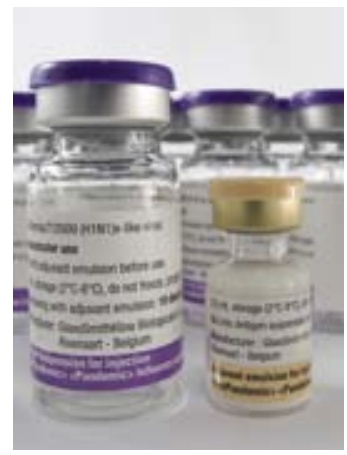

RESEARCH, 10.1136/bmj.c7297

\section{John M Watson consultant}

epidemiologist and head,

Respiratory Diseases Department,

Health Protection Agency Health

Protection Services, London

NW9 5EQ, UK

john.watson@hpa.org.uk

Richard G Pebody consultant

epidemiologist, Immunisation

and Respiratory Diseases

Departments, Health Protection

Agency Health Protection Services

Competing interests: None

declared.

Provenance and peer review:

Commissioned; not externally

peer reviewed.

Cite this as: BMJ 2011;342:d545 doi: 10.1136/bmj.d545

\section{Read more on doc2doc's pandemic flu forum at http://bit.ly/hbOEoz}

Almost as soon as the new influenza A/H1N1 2009 virus was identified in April 2009, its pandemic potential was realised. ${ }^{1}$ Immediate steps were taken by vaccine manufacturers, working with the World Health Organization's network of influenza reference laboratories, and with regulatory and standardisation authorities, to develop a pandemic specific vaccine and manufacture enough to meet global needs. To make best use of the H1N1 antigen, low dose monovalent vaccines were developed with the addition of adjuvant to enhance immunogenicity. These vaccines became available towards the end of 2009. The first of several studies to assess the effectiveness of these pandemic influenza $\mathrm{A} / \mathrm{H} 1 \mathrm{~N} 1$ vaccines, including the linked study by Skowronski and colleagues, ${ }^{2}$ are now being published.

On the basis of the emerging epidemiological picture, pandemic vaccines were given to subsets of the population at higher risk of infection and severe disease according to national immunisation policies. In the United Kingdom, people with underlying health conditions that place them at increased risk from the complications of influenza, including those aged 65 years and over and, for the first time, pregnant women, were recommended to receive the monovalent pandemic vaccine. ${ }^{3}$ Later healthy children under 5 years were targeted. At the same time, surveillance to assess the effectiveness of these vaccines in protecting recipients against the H1N1 2009 infection was undertaken.

Skowronski and colleagues assessed the effectiveness of an adjuvanted monovalent influenza vaccine programme that began in late October 2009 just as peak activity had occurred; activity declined thereafter. ${ }^{2}$ Cases were patients presenting with an influenza-like illness in whom H1N1 2009 infection was confirmed by polymerase chain reaction testing of respiratory specimens, and controls were patients with a similar illness who tested negative. Information was collected on whether or not patients had received pandemic influenza vaccine two weeks or more before onset of illness, and on age, comorbidity, geographical location, timing of specimen collection (in relation to onset of illness), and week of illness onset to enable adjustment for confounders. The analysis of 209 cases and 343 controls reported an adjusted vaccine effectiveness of 93\% (95\% confidence interval 69\% to $98 \%$ ), with most recipients having received a single dose of vaccine.

This approach (test negative incident case-control study) to assessing the effectiveness of the influenza vaccine is feasible in any country where surveillance for influenza-like illness includes virological testing of a sample of cases. It can provide a rapid estimate of effectiveness, and although it requires the collection of a small dataset on all potential cases and controls, and laboratory examination of their specimens, it may be less resource intensive than other epidemiological approaches. As with all well conducted observational studies, the authors took care to ensure that the people included were representative of the population from which they were drawn. Major potential confounding factors that became apparent in previous studies were identified and adjusted for.

At $93 \%$, the estimate of protection in this study is higher than in three similar studies of the effectiveness of adjuvanted monovalent pandemic H1N1 2009 vaccine that were published recently. However, the estimates of protection against H1N1 infection in two of these studies fall within the confidence intervals of the Canadian study. A UK study estimated protection at $72 \%$ (21\% to $90 \%),{ }^{4}$ and a study with contributors from seven European countries reported protection at $71.9 \%$ (45.6\% to $85.5 \%) .^{5}$ This second study found no significant protection from the trivalent seasonal vaccine, which had no pandemic H1N1 2009 component. Another study from the UK with a similar design estimated protection to be $62 \%$ (33\% to $78 \%)$ at 14 days or more after immunisation. ${ }^{6}$ Pandemic vaccine, which takes about six months to produce, arrived after the initial pandemic wave occurred in these northern hemisphere countries. As a result, it had a reduced effect on preventing illness, although this varied according to the precise timing of activity in individual countries.

The threat of pandemic H1N1 infection did not disappear with the conclusion of those initial waves, however, as the recent 2010-11 seasonal activity in the UK and other European counties has shown. ${ }^{7}$ The pandemic vaccine has been used to supplement the updated trivalent vaccine in immunosuppressed groups. ${ }^{3}$ It has been even more valuable in making up the shortfall in supplies of trivalent vaccine in the UK, when demand increased as a result of influenza activity in which pandemic H1N1 2009 was the main cause of severe illness in children and adults under 65 years. One intriguing question, not yet answered, is the extent to which the adjuvanted monovalent pandemic vaccine given at the end of 2009 or in early 2010 has continued to provide protection against the H1N1 virus in the $2010-11$ season.

Despite these successes for the pandemic vaccine, the delay in its availability remains a problem. Steps to shorten the period between recognition of a virus with pandemic potential and the production of a safe specific vaccine have already been taken, and the potential to shorten this further is limited. Vaccines that protect against all forms of influenza are much needed. ${ }^{9}$

1 WHO. Influenza-like illness in the United States and Mexico. 2009. www who.int/csr/don/2009_04_24/en/index.html.

2 Skowronski DM, Janjua NZ, De Serres G, Hottes TS, Dickinson JA, Crowcroft N, et al. Effectiveness of AS03 adjuvanted pandemic H1N1 vaccine: case-control evaluation based on sentinel surveillance system in Canada, autumn 2009. BMJ 2011;342: c7297.

3 Department of Health. Influenza (updated 19 January 2011). In: Immunisation against infectious disease-the "green book." 2007. www.dh.gov.uk/en/Publicationsandstatistics/Publications/ PublicationsPolicyAndGuidance/DH_079917.

4 Hardelid P, Fleming DM, McMenamin J, Andrews N, Robertson C, Sebastianpillai P, et al. Effectiveness of pandemic and seasonal influenza vaccine in preventing pandemic influenza A(H1N1)2009 infection in England and Scotland 2009-2010. Euro Surveill 2011;16:pii:19763. 
5 Valenciano M, Kissling E, Cohen J-M, Oroszi B, Barret A-S, Rizzo C, et al. Estimates of pandemic influenza vaccine effectiveness in Europe, 2009-2010: results of Influenza Monitoring Vaccine Effectiveness in Europe (I-MOVE) multicentre case-control study. PLoS Med 2011;9:e1000388.

6 Andrews N, Waight P, Yung CF, Miller E. Age-specific effectiveness of an oil-in-water adjuvanted pandemic (h1n1) 2009 vaccine against confirmed infection in high risk groups in England. J Infect Dis 2011;203:32-9.
7 Health Protection Agency. HPA weekly national influenza report. 2011. www.hpa.org.uk/web/HPAweb\&HPAwebStandard/ HPAweb C/1287147913271.

8 European Centre for Disease Surveillance and Control. Weekly influenza surveillance overview (WISO). 2011. http://ecdc.europa.eu/EN/ HEALTHTOPICS/SEASONAL_INFLUENZA/EPIDEMIOLOGICAL_DATA/Pages/ Weekly_Influenza_Surveillance_Overview.aspx.

9 De Jong MD, Sanders RW. The future of influenza vaccines. BMJ 2009;339:b4014.

\section{Accessible medical research}

\section{New journal BMJ Open provides open access to even more research}

\begin{abstract}
Trish Groves deputy editor, $B M$ J editor in chief, BMJ Open eic.bmjopen@bmjgroup.com Competing interests: None declared.

Provenance and peer review: Commissioned; not externally peer reviewed.
\end{abstract}

Cite this as: BMJ 2011;342:d1190 doi: 10.1136/bmj.d1190
The world's first website was launched in August 1992 at info.cern.ch. With rapid growth of the world wide web over the following decade came the idea that articles reporting publicly funded research, particularly in health, ought to be accessible to anyone. Although

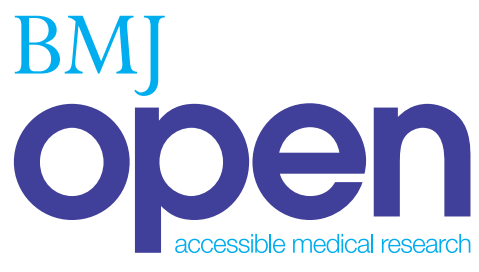
policy, or research agendas, and $B M J$ Open is happy to consider these. The journal also welcomes submission of preliminary or only locally relevant research, study protocols, early phase trials, and postmarketing studies-as long as they are well conducted and fully reported. All authors are expected many traditional publishers remain wary of this concept, at BMJ Group our approach has been to see what works best for readers, authors, and funders while still paying the bills. So, within two and a half years of the birth of the web, "eBMJ" was online at bmj.com, and in 1998 the BMJ became one of the first journals to provide full free access to all of its contents.

From 2005 bmj.com gradually introduced a pay wall for non-research articles, so that income from subscriptions could support continuing free access to research articles. ${ }^{1}$ In 2010 the $B M J$ introduced article processing fees for research articles, which apply only when authors can claim the money back, in full, from whoever funded the research. ${ }^{2}$

Our newest journal BMJ Open starts publishing its first articles this month. It is an open access journal for peer reviewed medical research from any discipline, which uses open peer review and posts reviewers' reports alongside published articles (http://bmjopen.bmj.com). BMJ Open has no print edition and no personal subscribers but asks authors to pay an article processing charge for each article that is accepted after peer review. The journal does, however, offer discounts or waivers on a case by case basis to authors with limited resources, particularly those in low and middle income countries covered by the HINARI Programme for Access to Health Research (www.who.int/ hinari/en/). It also offers discounts to reviewers who submit articles within a year of providing a timely review. As in the $B M J$, authors' ability to pay does not influence publication decisions, because fees are not levied until after an article is accepted.

BMJ Open publishes all types of research about clinical science, clinical practice, health policy, healthcare delivery, medical education, and research methodology. Journals with defined readerships, including the $B M J$ and other $B M J$ journals, decline many submissions because the editors feel the work will not be sufficiently interesting or useful to their readers. BMJ Open will not make such editorial decisions and will publish research that reviewers deem scientifically and ethically sound and deserving of publication.

Many robust studies reinforce rather than lead practice, to write their articles in line with a reporting statement, such as CONSORT or STROBE, whenever appropriate.

Publishing such studies with open access helps to complete the research record for clinicians, policy makers, systematic reviewers, and other researchers. That evidence base could be even more useful if researchers made their raw data available, something that the Wellcome Trust and other major international funders recently called for. ${ }^{3} B M J$ Open has adopted the BMJ's policy of encouraging authors to share additional data and raw data from their studies, ${ }^{4}$ and it plans to work with data experts to make this easier to do.

Meanwhile, the BMJ Group's other journals have developed "BMJ Unlocked," a service through which authors can pay open access fees to make their articles available to anyone online. And the full contents of all $B M J$ journals, including the $B M J$, are freely accessible to institutions in 113 low income and low-middle income countries through the group's membership of the HINARI initiative (http:// group.bmj.com/products/journals/countries-with-freeaccess). Furthermore, authors in all of our journals retain their copyright and receive royalties on any reprint sales, with the BMJ Group requiring only an exclusive licence to publish each article first and claiming related commercial rights (http://group.bmj.com/products/journals/instructions-for-authors/licence-forms).

In 2006 Peter Suber, academic and open access advocate, wrote " $B M J$ is a pioneer in OA [open access]. Because $B M J$ has supported OA when it could, and never lobbied against it, it doesn't have embarrassing anti-OA arguments to retract or customer cognitive dissonance to overcome." 5 The launch of BMJ Open is the next step in that journey.

1 Delamothe T. bmj.com behind access controls. BMJ 2004;329:814.

2 Godlee F, Groves T. Open access publication fees at the BMJ. BMJ 2010;341:c4494.

3 Walport M, Brest P. Sharing research data to improve public health. Lancet 2011;377:537-9.

4 Groves T. BMJ policy on data sharing. BMJ 2009;338:b1285.

5 Suber P. BMJ launches a hybrid OA journal program. Open Access News. 2006. http://legacy.earlham.edu/ peters/fos/2006/08/bmjlaunches-hybrid-oa-journal-program.html. 